\title{
АКТУАЛЬНЫЕ АСПЕКТЫ ОКАЗАНИЯ МЕДИЦИНСКОЙ ПОМОЩИ ПОЖИЛОМУ НАСЕЛЕНИЮ В ПЕРИОД ПАНДЕМИИ *
}

\author{
(C) 2020 Музалев С.B. \\ кандидат экономических наук, доцент Департамента бизнес-аналитики \\ Финансовый университет при Правительстве Российской Федерации, Россия, Москва \\ E-mail: SVMuzalyov@fa.ru \\ (c) 2020 Мустафаева C.P. \\ менеджер Департамента бизнес-аналитики \\ Финансовый университет при Правительстве Российской Федерации, Россия, Москва \\ E-mail: SRMustafaeva@fa.ru \\ (c) 2020 Шнайдер В.В. \\ кандидат экономических наук, доцент департамента магистратуры (бизнес-программ) \\ Тольяттинский государственный университет, Россия, Тольятти \\ E-mail: gerutti1881@mail.ru
}

Экономические, социальные и политические преобразования, произошедшие в России в 1990-е годы, имели пагубное воздействие на все социальные сектора, включая здоровье. Распад Советского Союза, радикальные изменения в политической системе и переход от централизованного планирования к рыночной экономике препятствовали устойчивому экономическому росту и политической стабильности.

Экономические и политические преобразования в начале 1990-х годов привели к значительному ухудшению здоровья и отсутствию финансовой защиты пожилого населения. Показатели сектора здравоохранения в России с начала 1990-х годов отражают экономические, политические и социальные преобразования, которые произошли в течение последних трех десятилетий. Первый этап, как было отмечено выше, этой трансформации - неблагоприятные последствия, доступ к медицинскому обслуживанию и финансовой защите пожилого населения. Последующий экономический рост, сокращение бедности и политические обязательства по улучшению охвата привели к постепенному улучшению, но с задержкой во времени.

Реформирование в части интересов пожилого населения с целью обеспечения всеобщего охвата услугами здравоохранения проводится во многих странах мирового пространства. Прогресс контролируется с помощью индикаторов оценки достижений в области защиты от финансовых рисков и доступа к качественным основным медицинским услугам. За последние два десятилетия в России значительно выросло финансируемое государством здравоохранение через различные программы, в том числе и Программу государственной гарантии медицинского обслуживания.

Программу государственных гарантий медицинской помощи следует считать универсальной программой, инвестирующей средства на развитие многоуровневой системы предоставления медицинских услуг. В настоящее время, пандемия COVID-19 оказывает огромное влияние на жизни людей во всем мире. Она повлияла не только на здоровье населения, но и на экономику, на многие мировые экономические процессы.

Можно сказать, что данное явление сегодня затронуло почти все сферы нашего общества, но в первую очередь это коснулось области здравоохранения. Пандемия COVID-19 коснулась устойчивости системы здравоохранения, эффективности проводимой политики в этой сфере в целом.

Ключевые слова: государственные гарантии, защита, качество услуг, медицинская помощь, население, пандемия, финансовые риски, учреждения здравоохранения, экономика.

\footnotetext{
* Статья подготовлена по результатам исследований, выполненных за счет бюджетных средств по государственному заданию Финансового университета
} 
В 90-х годах страна столкнулась с серьезными экономическими проблемами, кризис 1998 года и политическая слабость, страна изо всех сил пыталась определить новую глобальную и региональную позицию, национальную идентичность и эффективную экономическую модель. Система здравоохранения была непосредственно затронута этим переходом, с охватом и финансовой защитой ситуация резко ухудшилась.

«В целом, с начала 90-х годов прошлого века произошли значимые структурные изменения в экономике страны, переход от плановой экономики к рыночной, что сопровождалось ухудшением социально-экономического положения населения. Это негативно повлияло на состояние здоровья граждан. Здоровье населения прогрессивно ухудшалось, продолжительность жизни снижалась, численность населения сокращалась угрожающими темпами» [1-3].

В 2000-х годах экономика быстро росла, поддерживая улучшение социальных показателей. Сегодня Россия страна с уровнем дохода выше среднего и развивающимся средним классом, уникальным по своей экономической и политической модели.

Несмотря на сложную макроэкономическую ситуацию, правительство стремится углубить и укрепить достигнутые социальноэкономические выгоды.

Модель роста в России в 2000-х годах включала прочный социальный контракт. Государство сыграло значительную социальную роль в обеспечении благосостояния граждан. Граждане России получили пользу от введенных льгот.

Количественные данные, представленные в работе, показывают, что Россия в дальнейшем добилась значительных финансовых успехов. Значительное улучшение финансовой защиты произошло в конце 1990-х и начале 2000-х годов, когда темпы катастрофических расходов резко сократились. С тех пор прогресс замедлился.

Крупные инвестиции и реформы, связанные с программой государственных гарантий, в течение 2000-х годов способствовали достижению прогресса в области здравоохранения и смягчили изменение тенденций во время финансового кризиса. Фискальное перераспределение было использовано для увеличения распределения ресурсов в менее обеспеченных субъектах. Увеличение государственных расходов на больничную помощь помогло улучшить доступ к стацио- нарной помощи для бедных, особенно пожилых людей. Увеличение инвестиций в диагностику, оборудование в амбулаторно-поликлинических учреждениях связано с расширением доступа $\mathrm{K}$ услугам, хотя только в крупных городах. Стремление перераспределить расходы на первичную медицинскую помощь расширило доступ, как врачей, так и пожилого населения к услугам в сельской местности. Программа государственных гарантий предоставляет единый пакет преимуществ, на который все россияне имеют право согласно Конституции. На практике недофинансирование и отсутствие ясности в отношении пакетов льгот приводит к неявному нормированию здравоохранения из-за неадекватного доступа к качественному здравоохранению и к доступным лекарствам. Безусловно, требуется дополнительное фискальное пространство для политики здравоохранения, которое должно более эффективно использовать имеющиеся ресурсы. Расширение охвата амбулаторными препаратами и укрепление первичной медикосанитарной помощи являются неотложными приоритетами.

Пытаясь устранить недостатки в отношении пожилого населения, Пенсионный фонд Российской Федерации (далее - ПФРФ) в 2003 году начал участвовать в финансировании покрытия обязательного медицинского страхования для пенсионеров примерно в десятке регионов. Это число выросло до 32 в 2004 году. ПФРФ настаивал на поддержании личных счетов застрахованных пенсионеров и использовании специальных способов оплаты для облегчения мониторинга расходов, и обеспечение того, чтобы средства ПФРФ, введенные в систему, не направлялись на другие цели. В соответствии с договоренностями, принятыми в 2005 году, регионы теперь несут ответственность за внос вкладов в систему обязательного медицинского страхования.

«Начиная с 2006 г. наметились положительные тенденции в демографической ситуации, складывающейся в России» [4]. Положительные изменения демографической ситуации сформировались за счет естественного и миграционного прироста населения. Однако, как отмечает ряд авторов «данный период был ознаменован снижением рождаемости и в 2014 году составил $-13,3 \%$, в 2015 г., показатель не изменился, но продолжил снижение до 12,9\%о в 2016 г.» [5]. Распределение населения Российской Федерации по возрастным группам на 01.01.2019 года 
(\% от общего населения) представлено на рисунке 1 [6].

Правительством Российской Федерации населению постоянно оказывается поддержка в части оказания медицинской помощи. Медицинские учреждения своей целью определяют качество и оперативность предоставления медицинских услуг, несмотря на ряд факторов внешнего значения корректирующих действия медучреждений.

Так, в настоящий момент при пандемии коронавирусной инфекции система здравоохранения испытывает колоссальную нагрузку. Необходимо грамотно расставить приоритеты, мобилизовать все имеющиеся ресурсы, приложить все усилия для сохранения здоровья населения. Успешная реализация возникших перед медицинскими организациями задач, раскрывающихся через факторы объективного и субъективного характера, которые накладывают отпечаток на эффективность использования недостаточных материальных и финансовых ресурсов в медицине. Анализ финансовой деятельности медицинской организации устанавливается через эффективные управленческие решения, направленные на решение важных вопросов по оказанию медицинской помощи населению в условиях пандемии.

Пандемия внесла значительные коррективы в деятельность всех медицинских организаций, направленных на реализацию мер по своевременной диагностике и лечению. В связи, с чем были внесены изменения в оказании плановой медицинской помощи по заболеваниям, не свя- занным с COVID-19. Это было сделано в целях защиты пациентов от угрозы распространения новой инфекции.

«На федеральном уровне приняты важнейшие решения, необходимые для сохранения финансовой устойчивости системы здравоохранения» - отметила председатель ФОМС Елена Чернякова [7]. Сегодня от слаженных действий исполнительных органов власти в сфере здравоохранения, территориальных фондов ОМС и медицинских организаций во многом зависит ситуация, связанная с коронавирусной инфекцией на местах.

В связи с этими изменениями, более 400 млн. рублей из средств ОМС, предусмотренных во втором квартале 2020 года на профилактические мероприятия, будут перенаправлены на финансирование поликлиник для работы в условиях пандемии в рамках подушевого финансирования. Данное перераспределение будет продолжено при условии дальнейшего сохранения сложной эпидемиологической ситуации.

К снижению объемов поступления денежных средств в медицинские организации приводит сокращение объемов плановой медицинской помощи. Образуются значительные объемы «выпадающих доходов» для медицинских организаций, в т.ч. при закрытии на карантин, вследствие эпидемиологической обстановки.

Для того чтобы опередить неблагоприятные последствия дефицита средств, принято решение о $100 \%$ авансировании медицинских организаций, вне зависимости от выполненных объемов медицинской помощи. Это означает, что

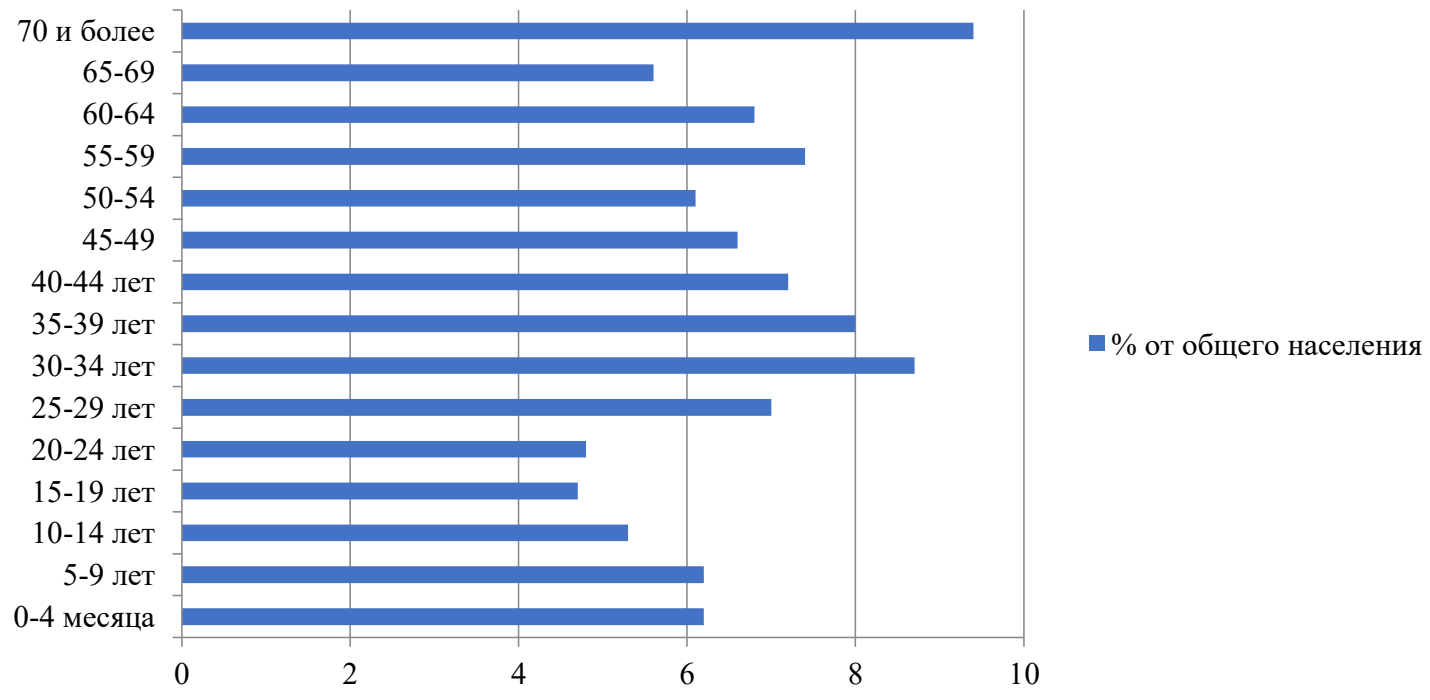

Рисунок 1. Динамика возрастных групп населения Российской Федерации на 01.01.2019 г. 
до улучшения эпидемической ситуации медицинские организации республики, работающие в системе ОМС, финансирование будут получать авансом в полном объёме. Эти деньги пойдут, в том числе, оплату труда медицинским работникам, погашение счетов за коммунальные услуги, оплату контрактов на приобретение медикаментов и расходных материалов.

Во всех медицинских учреждениях проводится масштабная работа по организации медицинской помощи в условиях пандемии COVID-19, в том числе по перепрофилированию коечного фонда. Для финансового обеспечения оказанной медицинской помощи при лечении COVID-19 приняты дифференцированные тарифы: при легком течении стоимость - 231719 руб., при среднем - 424818 руб., при тяжелом 463438 руб.

Развернута массовая лабораторная диагностика на коронавирус, проводится более 1000 анализов в день. Все лаборатории, диагностирующие COVID-19, будут включены в систему OMC. Учреждения здравоохранения несут дополнительные расходы в связи с пандемией: приобретение медикаментов и других, материальных запасов, в том числе средств индивидуальной защиты, расходных материалов для организации карантинных мероприятий, а также на выплаты заработной платы медицинским работникам. Закон «О внесении изменений в отдельные законодательные акты Российской Федерации по вопросам предупреждения и ликвидации чрезвычайных ситуаций» № 98-Ф3 от 01.04.2020 г. [8], устанавливает «механизм дополнительного финансового обеспечения медицинских организаций, связанных с изменением деятельности в условиях угрозы COVID-19» [9]. В тоже время обуславливается дефиниция «недополученные доходы». Источник финансирования «недополученного дохода» определен средствами федерального бюджета. Федеральным фондом обязательного медицинского страхования установлена методика определения объемов финансирования данного направления.

В заключение хотелось бы отметить, что дополнительные государственные средства можно изыскать из обычных бюджетных источников или национальных резервов (фондов непредвиденных расходов). Некоторые страны приостанавливают действие национальных инструментов контроля долговой нагрузки и дефицита бюджета для упрощения доступа к ресурсам. Также, необходимо наладить процессы для обеспечения координации, взаимодополняемости и согласования средств в целях принятия комплексных общегосударственных ответных мер, охватывающих все органы здравоохранения и финансовые учреждения. В свою очередь, органы здравоохранения и финансовые учреждения должны тесно сотрудничать друг с другом для того, чтобы перераспределение средств осуществлялось на выборочной основе в рамках деятельности, не требующей срочной помощи, а не за счет общих сокращений всех статей расходов, а для подготовки надежных смет расходов в связи с перераспределением средств на цели здравоохранения, и для быстрого реагирования в случае необходимости дополнительных ассигнований. А самое важное в данной ситуации - это недопущение снижения уровня медицинской помощи пожилому населению.

\section{Библиографический список}

1. Щепина О.П., Медина В.А. Здоровье населения региона и приоритеты здравоохранения. М.: ГЭОТАР- Медиа; 2012.

2. Население России 2012: двадцатый ежегодный демографический доклад / отв. ред. А. Г. Вишневский; Нац. исслед. ун-т «Высшая школа экономики». М.: Изд. дом Высшей школы экономики; 2014.

3. Население России 2013: двадцать первый ежегодный демографический доклад. М.: Изд. дом Высшей школы экономики; 2015.

4. Об итогах работы министерства здравоохранения Российской Федерации в 2015 году и задачах на 2016 год. Москва. Апрель 2016 г.

5. Аполихин О.И., Москалева Н.Г., Комарова В.А. Современная демографическая ситуация и проблемы улучшения репродуктивного здоровья населения России. Экспериментальная и клиническая урология. 2015; (4): 4-14.

6. Челухина Н. Ф. Страхование финансовых рисков человеческого капитала в России. Монография. Москва. Русайнс. 2016. http://dlib.rsl.ru/rs101009000000/rs101009481000/rs101009481542/rs101009481542.pdf 
7. Наша главная задача - сохранить финансовую устойчивость системы здравоохранения / http://www.ffoms. gov.ru/news/ffoms/elena-chernyakova-nasha-glavnaya-zadacha-sokhranit-finansovuyu-ustoychivost-sistemyzdravookhraneniya/(дата обращения 16.07.2020).

8. Федеральный закон от 01.04.2020 N 98-Ф3 (ред. от 08.06.2020) «О внесении изменений в отдельные законодательные акты Российской Федерации по вопросам предупреждения и ликвидации чрезвычайных ситуаций».

9. Правила обязательного страхования в целях борьбы с угрозой распространения новой коронавирусной инфекции COVID-19 скорректированы, говорится в сообщении ФОМС. РИА Новости, 21.04.2020.

10. Петров А.М. «КОНТРОЛЬ ЗА ДВИЖЕНИЕМ ДЕБИТОРСКОЙ И КРЕДИТОРСКОЙ ЗАДОЛЖЕННОСТИ» Современный бухучет. 2004. № 9. С. 38.

11. Карпова Т.П., Петров А.М., Горбаткова Г.А., Самарина Л.Б., ДашкинаГ.Г., Сидорова М.И., Сабанин Р.Л., Ситникова В. А., Листопад Е. Е. «БУХГАЛТЕРСКИЙ УЧЕТ В СФЕРЕ УСЛУГ» учебник для студентов высшего профессионального образования, обучающихся по специальности 080109 «Бухгалтерский учет, анализ и аудит» / Под редакцией М.А. Вахрушиной; Министерство образования и науки Российской Федерации, Федеральное государственное учреждение «Федеральный институт развития образования». Москва, 2011. Сер. Читай

12. Петров А.М., МеЛьниковаЛ.А. «ФОРМИРОВАНИЕ ОТЧЕТНОСТИ В СООТВЕТСТВИИ С ТРЕБОВАНИЯМИ МСФО КАК ОБЪЕКТИВНАЯ НЕОБХОДИМОСТЬ НА СОВРЕМЕННОМ ЭТАПЕ РАЗВИТИЯ ЭКОНОМИКИ РФ» Проблемы современной экономики. 2017. № 2 (62). С. 105-107.

13. Петров А.М., Коняхин А. Н. «УЧЕТНАЯ ПОЛИТИКА ПРИ ПОДГОТОВКЕ ПЕРВОЙ ОТЧЕТНОСТИ СОГЛАСНО МСФО» Международный бухгалтерский учет. 2013. № 11 (257). С. 2-15.

14. Петров А.М., ЛЫмарь М. П. «СОСТАВ БУХГАЛТЕРСКОЙ ОТЧЕТНОСТИ В РОССИИ И КИТАЕ» МеЖДУНародНЫЙ бухгалтерский учет. 2014. № 31 (325). С. 28-37.

15. Петров А.М., ЛЫМарь М.П. «СРАВНИТЕЛЬНАЯ ХАРАКТЕРИСТИКА ОСНОВНЫХ ПОЛОЖЕНИЙ ЗАКОНОВ, РЕГУЛИРУЮЩИХ БУХГАЛТЕРСКИЙ УЧЕТ В КИТАЕ И РОССИИ» МеждУнароднЫЙ бухгалтерский учет. 2013. № 40 (286). C. 52-60.

16. Петров А.М., Лымарь М. П. «СРАВНИТЕЛЬНЫЙ АНАЛИЗ БУХГАЛТЕРСКОГО УЧЕТА АКТИВОВ В РОССИИ И КИТАЕ» Международный бухгалтерский учет. 2014. № 27 (321). С. 34-48.

17. Петров А.М. «ОБЩЕСТВЕННОЕ ПИТАНИЕ 6 в 1: учетная политика, документооборот, калькулирование себестоимости, бухгалтерский учет, налоги, отчетность» / А. М.Петров. Москва, 2011. Сер. Полное руководство бухгалтера

18. A.M. Petrov; L.M. Sembiyeva Organizational and methodical mechanism of internal audit of settlements in corporate systems / Bulletin of the National Academy of Sciences of the Republic of Kazakhstan,- Volume 2, 2020, Pages 119-127 (Web Of Science)

19. Z.A. Kevorkova; G. S.Zhukova; O. Antonova; A. M. Petrov Organizational prerequisites for transition to IFRS in the artificial intelligence context / The Bulletin of the National Academy of Sciences of the Republic of Kazakhstan Volume 2, 2020, Pages 128-136 (Web Of Science) 
